\title{
Viability of Lactobacillus paraplantarum DSM 14485 in hu- man gastrointestinal tract and its molecular and biochemical identification after fermented vegetable consumption
}

\author{
Marja Tamminen ${ }^{1)}$, Arthur C. Ouwehand ${ }^{2)}$, Maarit Mäki ${ }^{3)}$, Tiina Joutsjoki ${ }^{4)}$, Marietta Sjöblom ${ }^{5)}$, \\ Kaija Nissinen ${ }^{6)}$ and Eeva-Liisa Ryhänen ${ }^{7)}$ \\ MTT Agrifood Research Finland, Biotechnology and Food Research, Alimentum, Fl-31600 Jokioinen, Finland \\ ${ }^{1}$ Corresponding author, current address: University of Turku, Department of Biochemistry and Food Chemistry, \\ FI-20014 University of Turku \\ e-mail:mttammi@utu.fi,
}

\begin{abstract}
In this study the viability of a potentially probiotic Lactobacillus paraplantarum DSM 14485 in the intestinal tract of 22 healthy test subjects was qualitatively assessed in a randomised double blinded cross-over study design lasting $2 \times 4$ weeks (interventions I and II) with a 4-week washout period. The subjects were given in their diet either spontaneously fermented vegetables (SF) or vegetables fermented by starter bacteria which contained Lb. paraplantarum DSM 14485 (P). The numbers of lactic acid bacteria (LAB) in fecal samples were at the level of $10^{5} \mathrm{cfu} \mathrm{g}^{-1}$ in both groups. The presence of $L b$. paraplantarum DSM 14485 was confirmed by biochemical and molecular methods. We were able to show that $L b$. paraplantarum DSM 14485 , isolated from spontaneously fermented cucumbers, was viable in the intestine of ten test subjects after taking P-diet when the numbers of LAB were sufficiently high in the product.
\end{abstract}

Key words: identification, lactic acid bacteria, fermented foods, vegetables, intestinal micro-organisms

\section{Introduction}

Vegetables are good sources of fermentable carbohydrates for lactic acid bacteria (LAB) (Yoon et al. 2006) and $L A B$ inoculants have been used for fermentation of vegetables for human consumption (Gardner et al. 2001). LAB also generate additional vitamins (Jägerstad et al. 2004) and low calorie sugars (Weymarn et al. 2002) in these products.

$L A B$ can improve the shelf life and the quality of vegetables. Some strains of $L A B$ decrease biogenic amines in fermented cabbage (Spicka et al. 2002), although others may have the potential to produce them (Bover-Cid and Holzapfel 1999). Also, the content of glucosinolate breakdown products in sauerkraut varies depending on sour agents used in products (Tolonen et al. 2004).

Specific LAB may have probiotic effects e.g. stimulation of immune response against various diseases (Isolauri et al. 1995, Kankaanpää et al. 2003), reduction of the risk of food allergies (Kalliomäki and Isolauri 2002), alleviation of lactose intolerance symptoms (Jiang and Savaiano 1997), prevention of urinary tract infections (Bruce and Reid 1988) and antitumor activity (Asano et al. 1986).

Most strains of the Lactobacillus plantarum-group have been shown to be highly tolerant to acid, alkaline and osmotic stress and highly sensitive to detergent stress, although substantial diversity can been 


\section{AGRICULTURAL AND FOOD SCIENCE}

M. Tamminen et al. (2012) 21: 182-196

found for other stresses (Parente et al. 2010). Lb. plantarum used as starter in cabbage juice was able to survive at $4 \stackrel{\circ}{\circ} \mathrm{C}$ and $\mathrm{pH} 3.6$ for four weeks at a level of $10^{7} \mathrm{cfu} \mathrm{mL}^{-1}$ (Yoon et al. 2006). Lb. plantarum has survived for $90 \mathrm{~d}$ at pH from 4.0 to 3.5 on artichokes in a brine and in simulated gastric juice (Valerio et al. 2006). Lactobacillus spp. are among the most frequent and best characterized micro-organisms used as probiotic and may alter the microbiota of host by implantation or colonization (Schrezenheimer and de Verse 2001). Viability of a probiotic strain in the intestine is an important criterion for the functionality of probiotics (Saxelin et al. 2010).

The aim of this study was to develop reliable, fast and economic methods for screening and identification of LAB from large number of isolated strains from clinical origins. This work was part of a larger clinical trial studying potential health effects of traditionally fermented vegetables and fermented vegetables containing a potential probiotic strain, Lb. paraplantarum DSM 14485 (Nissinen et al. 2003). Lb. paraplantarum is typical in fermented vegetable matrices (Bringel et al. 2005, Gharaei-Fathabad and Eslamifar 2011). The investigated strain was isolated from fermented cucumbers. It was used successfully as a starter in vegetable fermentations and it could be used in wide range of vegetable products suitable for lactoseintolerant people and vegetarians. Also pharmaceutical applications could be developed, because $L b$. paraplantarum DSM 14485 has shown essential in vitro probiotic qualities such as tolerance of bile salts, pancreatic juice and acidity, and adhesion to human intestinal mucus (Joutsjoki et al. 2003).

Several physiological and molecular methods were tested to identify this bacterial strain and the tests were compared with each other from economical and practical point of view. To fingerprint isolated strains, multiplex-PCR, rep-PCR and RAPD-PCR-analysis were obtained as useful methods (Bringel et al. 2005, Mäkimattila et al. 2011, Parente et al. 2010) so as Torriani et al. (2001a) used combination of RAPD-PCR patterns with ALFP effectively in differentiation strains of $L b$. plantarum-group. In this study PFGE was tested for Lb. paraplantarum DSM 14485.

\section{Materials and methods}

\section{Sources of $L A B$}

The aim of the clinical study was to determine the effects of two production methods of fermented vegetables (spontaneous and starter fermentation) on indicators of metabolic activity of intestinal microbiota, some parameters of nutritional status and acceptability of these products by healthy subjects. The study was approved by the ethical committee of University of Kuopio and Academical Central Hospital of Kuopio. A randomized, double blinded, cross-over study lasted $2 \times 4$ weeks with a 4-weeks washout period and 2 weeks run-in period. Feces were collected at the end of each period from 22 healthy subjects (Fig. 1). The diet contained vegetable products which were fermented by LAB starters including potentially probiotic Lb. paraplantarum DSM 14485, which was earlier identified as Lb. paraplantarum DSM 14485 (Joutsjoki et al. 2003 ). During interventions, subjects consumed daily $100 \mathrm{~g}$ of fermented vegetables (sauerkraut or salad mixture prepared from sliced carrots and grated swede) and $200 \mathrm{~g}$ of juice prepared from mixture of pressed sauerkraut and from 20 to $27 \%$ of heat treated carrot juice, or carrot juice alone fermented either spontaneously or with $L$ b. paraplantarum DSM 14485 . Sauerkraut was packed the same time for the both interventions and stored in a freezer at $-25 \stackrel{\circ}{ } \mathrm{C}$. For the intervention I, carrot juice and salad mixture were prepared in two lots, whereas for intervention II the products were prepared in one lot. Intervention I was followed by a wash out period of four weeks. The products were stored frozen. Intervention II was carried out in the same manner as intervention I. The screening procedure of fecal samples is summarized in Figure 2. The basic health status of tests subjects is described in Table 1. 


\section{AGRICULTURAL AND FOOD SCIENCE}

M. Tamminen et al. (2012) 21: 182-196

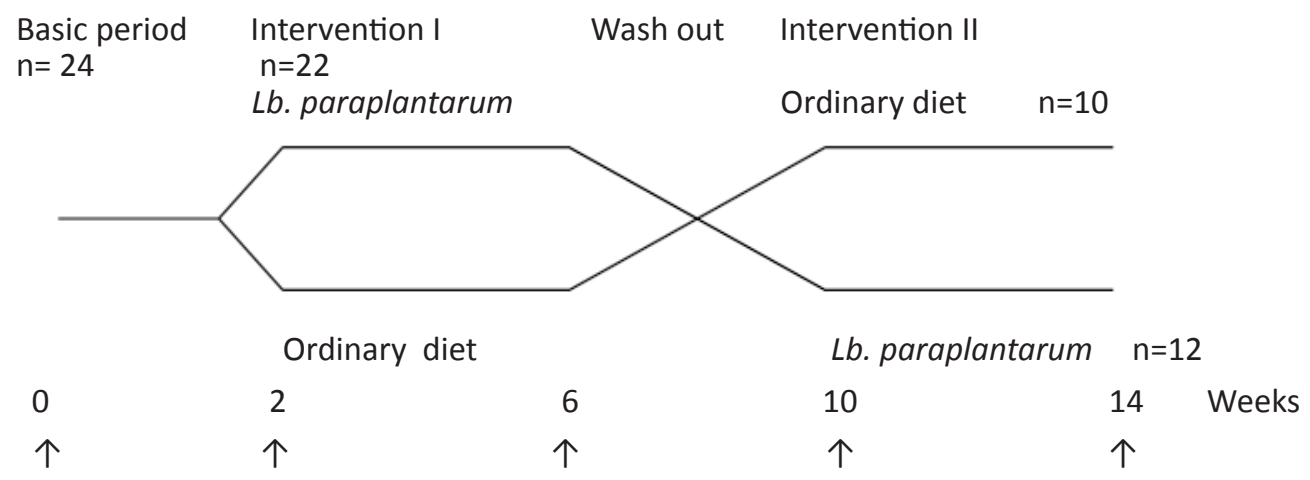

Fig. 1. Path of the test procedure in clinical trial. $\uparrow$ The point of feces samples.

Table 1. The basic health status of test subjects at the beginning of investigation $(n=24)$.

Two of the subjects interrupted the test before interventions. All test subjects were women.

\begin{tabular}{ll} 
Parameter & Average \pm SD \\
\hline Age & $39 \pm 9(20-54)$ \\
Weight $(\mathrm{kg})$ & $66.4 \pm 9.2(50.5-86.7)$ \\
& $24.4 \pm 3.9(19.7-34.1)$ \\
Weight index $\left(\mathrm{kg} \mathrm{m}^{-2}\right)$ & $118 \pm 10(96-147)$ \\
Systolic blood pressure (mmHg) & \\
\hline $\begin{array}{l}\text { Diastolic blood pressure } \\
(\mathrm{mmHg})\end{array}$ & $79 \pm 9(61-95)$ \\
\hline
\end{tabular}

\section{Microbiological methods}

LAB from fecal samples were analyzed at the University of Kuopio fresh or after storage at $-70^{\circ} \mathrm{C}$ on de Man, Rogosa, Sharpe (MRS, LabM) agar plates (NMKL 140:1991). The agar plates were sent to MTT for further analysis. Several colonies (4-6) from each fecal sample were collected and purified on MRS-agar plates (Difco Laboratories) incubated anaerobically for 2 days at $30^{\circ} \mathrm{C}$. Purified cultures were stored at $-70^{\circ} \mathrm{C}$ in MRS-broth containing 15\% glycerol. Reference strains were obtained from type culture collections: $L b$. plantarum DSM 20174, Lb plantarum 8014 TNO 96111, Lb. plantarum 8014 TNO 96111, Lb. plantarum NCDO 1193. LAB in fermented vegetables were enumerated at MTT by cultivation on MRS-agar plates incubated anaerobically for 3 days at $30^{\circ} \mathrm{C}$ 


\section{AGRICULTURAL AND FOOD SCIENCE}

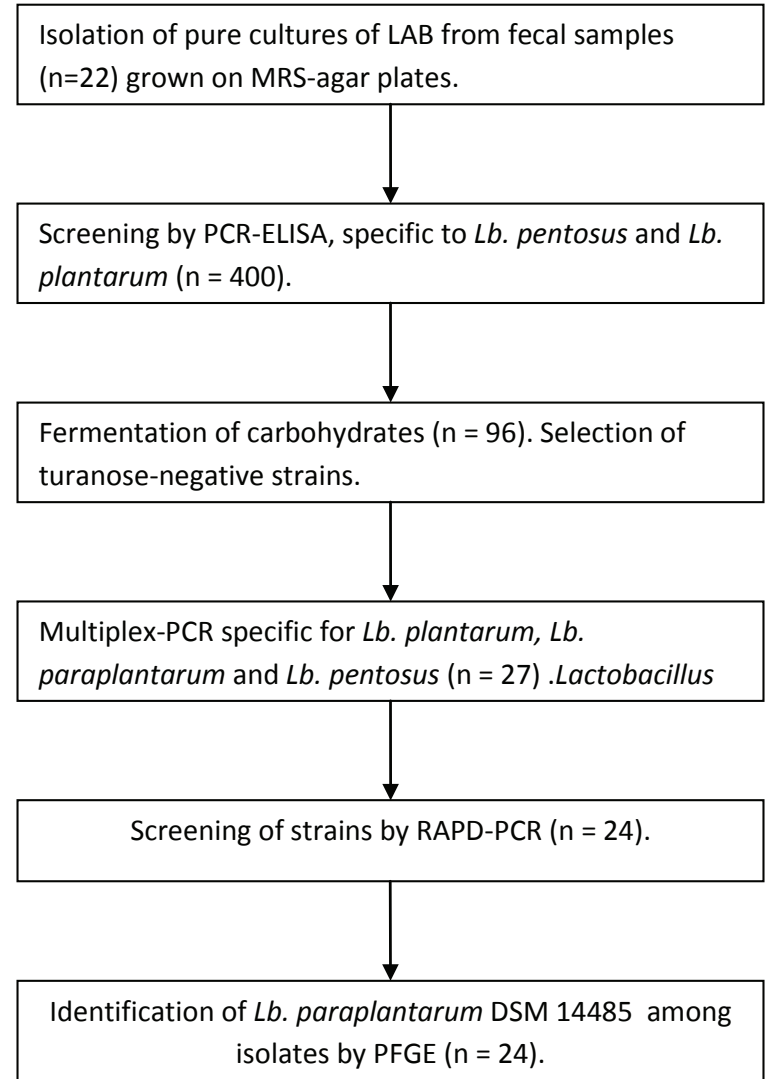

Fig. 2. Flow chart of the test procedure. The number of tested isolates in parenthesis.

\section{Molecular and biochemical identification of LAB}

Identification of LAB from fecal samples was carried out in six steps in order to show the viability of $L b$. paraplantarum DSM 14485 in human gastrointestinal tract (Fig. 1). Isolated pure cultures (about 400), were first screened by PCR-ELISA to identify members of the $L b$. plantarum-family using universal primers of 23 S rRNA (Ehrmann et al. 1994) and Lab 448, specific probe to Lactobacillus pentosus and Lb. plantarum-species (Hertel et al. 1991). In the next step 96 strains identified as Lb. plantarum / Lb. pentosus were studied for their fermentation of sugars in basic medium using chlorophenol red as an indicator (Table 2). Sugars for the test, D-sorbitol, D-turanose, inulin, L-arabinose, D-raffinose and D-glucose (positive control), were selected according to their ability to differentiate $L b$. plantarum-strains (Validov et al. 1998). Media (200 $\mu \mathrm{l})$ were inoculated with $3 \mu \mathrm{l}$ of overnight grown culture and incubated anaerobically in microtitreplates about $48 \mathrm{~h}$ at $30^{\circ} \mathrm{C}$. 


\section{AGRICULTURAL AND FOOD SCIENCE}

M. Tamminen et al. (2012) 21: 182-196

Table 2. Basic sugar broth used in identification of lactic acid bacteria. The $\mathrm{pH}$ of this medium was adjusted to $\mathrm{pH} 6.5$ and sterilized by autoclaving at $121^{\circ} \mathrm{C}$ for $20 \mathrm{~min}$.

\begin{tabular}{|c|c|}
\hline Component & to $100 \mathrm{ml}$ distilled water \\
\hline Casein peptone & $1 \mathrm{~g}$ \\
\hline Yeast extract & $0.4 \mathrm{~g}$ \\
\hline $\mathrm{K}_{2} \mathrm{HPO} * 3 \underset{2}{\mathrm{H}} \mathrm{O}$ & $0.2 \mathrm{~g}$ \\
\hline Sodium acetate $\left(\mathrm{NaCH}_{3} \mathrm{COOH}\right)$ & $0.25 \mathrm{~g}$ \\
\hline Tri-ammoniumcitrate $\left(\mathrm{C}_{6} \mathrm{O}_{7} \mathrm{H}_{5}(\mathrm{NH})_{3}\right)$ & $0.24 \mathrm{~g}$ \\
\hline Tween 80 & $0.1 \mathrm{ml}$ \\
\hline $\mathrm{MgSO}_{4} * 7 \mathrm{H}_{2} \mathrm{O}$ & $20 \mathrm{mg}$ \\
\hline $\mathrm{MnCl}_{2} * 4 \underset{2}{\mathrm{H} \mathrm{O}}$ & $4.4 \mathrm{mg}$ \\
\hline Chlorophenol red & $4 \mathrm{mg}$ \\
\hline
\end{tabular}

For the identification by multiplex-PCR, over night cultures of LAB (MRS broth at $30{ }^{\circ} \mathrm{C}$ ) were lysed by shaking with glass beads. Template used in PCR reactions were lysates of bacteria using disintegration of cells by glass beads shaking in a cell mill. Total-DNA was isolated by phenol extractions for RAPD and multiplex-PCR (Tamminen et al. 2004).

The members of $L b$. plantarum-family were identified by species-spesific PCR-method (Torriani et al. 2001b). Primers for $L$ b. plantarum, $L$ b. paraplantarum and $L$ b. pentosus were available (TAG Copenhagen A/S Symbion, Denmark). Taq polymerase (Promega Corporation, Madison WI, USA) was used in PCR amplifications (Programmable Thermal Controller PTC-100-60, MJ Research Inc., Massachusetts, USA). Electrophoresis was performed using a 1.2\% agarose gel and TAE buffer in $80 \mathrm{~V}$ potential $1.5 \mathrm{~h}$. The amplifications of Lactobacillus-strains from feces were verified with those of other Lactobacillus-strains ( $L b$. plantarum-strains: 8014 TN096111, 80 TNO9611, DSM 20174 and Pho 9, Lb. pentosus Vegstart 60 and Vegstart 10 (Chr Hansen A/S, Hørsholm Denmark) and Lb. plantarum strains isolated from fermented cucumbers (investigation of MTT, Food Research) and Lactobacillus brevis DSM 20054 -strain.

For RAPD-PCR -reactions amplification was done by primers (GTG) and ACGCGCCCT. The amplification conditions and primers for these reactions were as described by Johansson et al. (1995 a) and Gevers et al. (2001) using Taq polymerase. Samples $\left(0.5 \mu\right.$ diluted in $\left.9.5 \mu \mathrm{H}_{2} \mathrm{O}\right)$ were applied to the agarose gel $(1.2 \%)$ and the used potential was $120 \mathrm{~V}$ in electrophoresis (Bio-Rad Programmable Power supply, model 3000 Xi, Bio-Rad Laboratories, California, USA). The same strains were used to verify amplification 


\section{AGRICULTURAL AND FOOD SCIENCE}

M. Tamminen et al. (2012) 21: 182-196

profiles from the multiplex-PCR verification. Strains studied by RAPD-PCR were screened by carbohydrate fermentations and selected isolates that fermented D-turanose were chosen as reference for RAPD-analysis.

The PFGE-method was adapted from Tynkkynen et al. (1999). In short, DNA was isolated in agarose blocks, digested and subsequently analyzed by electrophoresis. Restriction enzyme Asc I (Biolabs, New England, USA) was used for the digestion of bacterial DNA. The results from RAPD- and PFGE-electrophoresis were analyzed by Bionumerics (Applied Maths, Sint-Martens-Latem, Belgium). The parameters used in PFGE were two different combinations: 1) pulse time 1.0-10.0 s, experiment time $20.5 \mathrm{~h}$ and voltage $5.5 \mathrm{~V} / \mathrm{cm}$ and 2) pulse time $5-15 \mathrm{~s}$ experiment time $20.5 \mathrm{~h}$ and voltage $5.5 \mathrm{~V} \mathrm{~cm}^{-1}$ (Bio-Rad, CHEF-DR III).

For accuracy, it is appropriate to use multiple techniques, working on species specific level (16sRNA, DNADNA-hybridization or PCR) and on strain level to obtain a detailed fingerprint of individual isolates (PFGE, RFLP or RAPD) (Temmerman et al. 2004).

\section{Results}

\section{Numbers of LAB}

LAB contents of products were analyzed at the beginning and the end of interventions (Fig. 3). The desired level of $L A B$, from 7 to $8 \mathrm{lg} \mathrm{cfu} \mathrm{g}^{-1}$, was detected in carrot juice samples, whereas the numbers decreased or were at the low level in other products. Spontaneously fermented carrot juice (SF) contained during intervention I $8.7 \mathrm{~g} \mathrm{cfu} \mathrm{g}^{-1}$ (geometric mean) and intervention II $8.2 \mathrm{Ig} \mathrm{cfu} \mathrm{g}^{-1}$ of LAB, while carrot juice fermented by $L b$. paraplantarum DSM 14485 (P) contained 8.7 and 7.4 lg cfu $\mathrm{g}^{-1}$, correspondingly. The numbers of $L A B$ in fecal samples have been reported by Nissinen et al. (2003). In samples collected from test subjects who ate SF-products, the average LAB numbers in interventions I and II were $5.22 \pm 1.05$ (n $=19$ ) at the beginning and $4.82 \pm 0,83(n=21) \mathrm{lg} \mathrm{cfu} \mathrm{g}^{-1}$ at the end of period, and $5.42 \pm 0.82(n=21)$ and $5.16 \pm 0.76(n=21) \lg$ cfu g $^{-1}$ correspondingly from subjects who ate P-products.

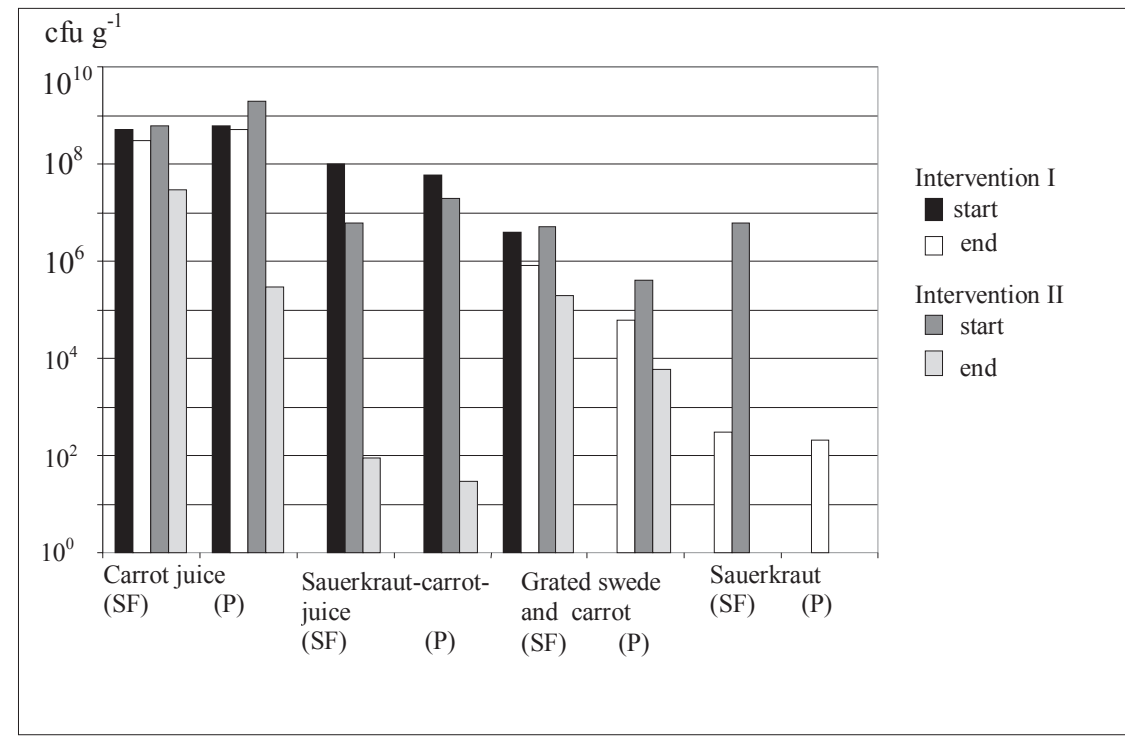

Fig. 3. Contents of LAB in fermented vegetable products at the start and the end of the interventions I and II. Spontaneous fermented (SF) and potential probiotic (P) products. 


\section{AGRICULTURAL AND FOOD SCIENCE}

M. Tamminen et al. (2012) 21: 182-196

The screening of approximately 400 isolates from the faecal samples was carried out by PCR-ELISA. Of these, 96 showed absorbance (OD $600 \mathrm{~nm}$ ) over 0.1 and were further tested for their carbohydrate fermentation profiles. The reference strains showed different fermentation profiles from $L b$. paraplantarum DSM 14485, which does not ferment D-turanose. Of the 96 tested isolates, 65 were unable to ferment $D$-turanose. These isolates were tested for their ability to ferment the other sugars. Based on these results, 27 isolates were selected for further studies.

\section{Multiplex-PCR}

The detection of $L b$. paraplantarum DSM 14485 amplified 107 bp fragment typical for $L b$. paraplantarum (Tamminen et al. 2003). This strain was earlier identified as Lb. plantarum by API CHL 50 test (Joutsjoki et al. 2003). $L$ b. plantarum and $L$ b. paraplantarum are phylogenetically very close as is $L b$. pentosus. The reference strains amplified typical fragments for their species but the strain isolated from fermented cucumbers which was identified $L b$. pentosus by API CHL-test amplified 318 bp fragment typical for $L b$. plantarum. Among the tested 27 isolates, 24 were identified as $L b$. paraplantarum and 3 isolates as $L b$. plantarum. Amplifications of multiplex-PCR are shown in Figure 4.
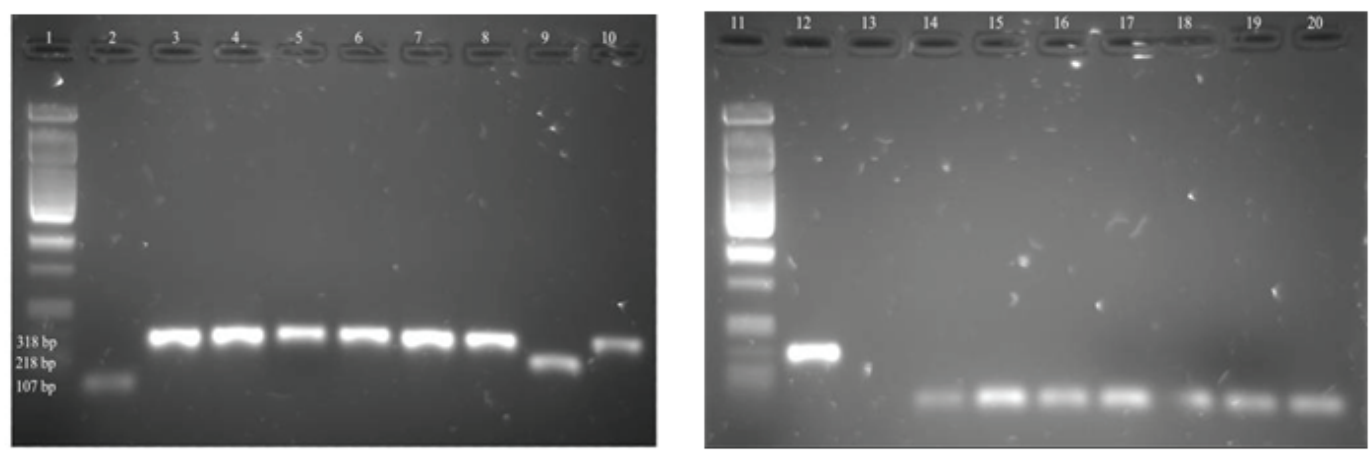

Fig. 4. Multiplex-PCR amplification of Lb. plantarum-related lactobacilli isolated from fecal samples. Lanes 1 . and 11.: $\lambda$ Pst I molecular weight marker, line 2.: Lb. paraplantarum DSM 14485, lines 3.-8. Lb. plantarum -strains (8014 TNO96111, 80 TNO9611, DSM 20174 and Pho 9), line 9: Lb. pentosus Vegstart 60, lines 10. And 12.: Lb. plantarum strains isolated from fermented cucumbers, line 13: Lb. brevis DSM 20054 -strain and 14.-20.: strains isolated from fecal samples.

\section{RAPD -PCR}

PCR-reactions were tested using both total DNA and lysate from the tested isolates. The total-DNA for RAPD -reactions was chosen as template. DNA was isolated from 31 strains screened by carbohydrate fermentations including also isolates ( $2 \mathrm{Lb}$. paraplantarum and $2 \mathrm{Lb}$. plantarum -isolates) which had different carbohydrate profiles from Lb. paraplantarum DSM 14485. Total 27 Lb. paraplantarum -isolates and $4 \mathrm{Lb}$. plantarum isolates from fecal samples were used as reference in these RAPD -analyses. The results were calculated by Pearson product moment correlation coefficient $(r)$ and position tolerance was $1 \%$. 


\section{AGRICULTURAL AND FOOD SCIENCE}

M. Tamminen et al. (2012) 21: 182-196

When ACGCGCCCT-primer was used in amplification with $L$ b. paraplantarum DSM 14485 length of bands were 1049 bp, 706 bp and 412 bp. There were 9 isolates $(48 / 4,61 / 2,43 / 1,47 / 2,44 / 1$, 54/2, 61/1, 24/1, $44 / 2$ ) in the same cluster with $L$ b. paraplantarum DSM 14485 with $87 \%$ similarity (Fig. 5). When (GTG) $)^{5}$ -primer was used there were five bands: $1116 \mathrm{bp}, 910 \mathrm{bp}, 754 \mathrm{bp}$, and $627 \mathrm{bp}$ and $413 \mathrm{bp}$. Six isolates $(33 / 2,61 / 2,61 / 1,48 / 4,24 / 1)$ from test group samples showing over $48 \%$ similarity with Lb. paraplantarum DSM 14485 (Fig. 6.). ACGCGCCCT -primer differentiated the isolates more than (GTG) ${ }^{5}$-primer so only one isolate differed between these clusters of two different primers (Fig. 7).
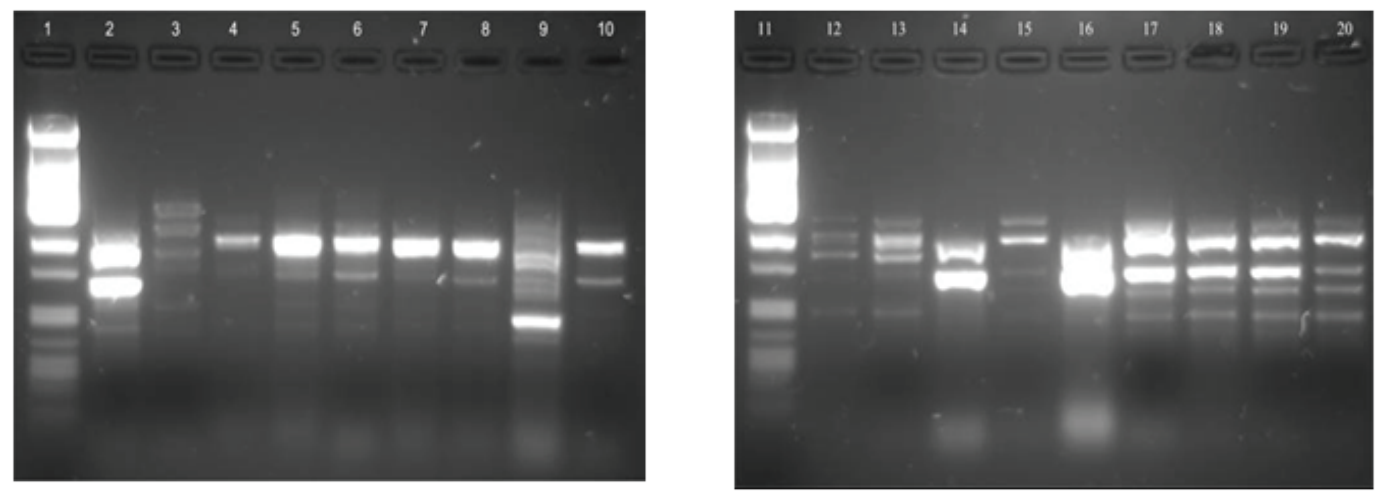

Fig. 5. RAPD-PCR-amplifications of fecal Lactobacillus strains by (GTG) $)_{5}$-primer. Lines 1. and 11.: $\lambda$ Pst I molecular weight marker, line 2. Lb. paraplantarum DSM 14485, line 3. Lb. brevis DSM 20054, lines 4 - 9 Lb. plantarum strains: 8014 TNO96111, 80 TNO9611, DSM 20174, NCDO 1193, Pho 9, Vegstart 60, line 9: Lb. pentosus VegStart 60 lines 10 and 12: $\mathrm{Lb}$. plantarum strains isolated from fermented cucumbers and 14.-20.: strains isolated from fecal samples.
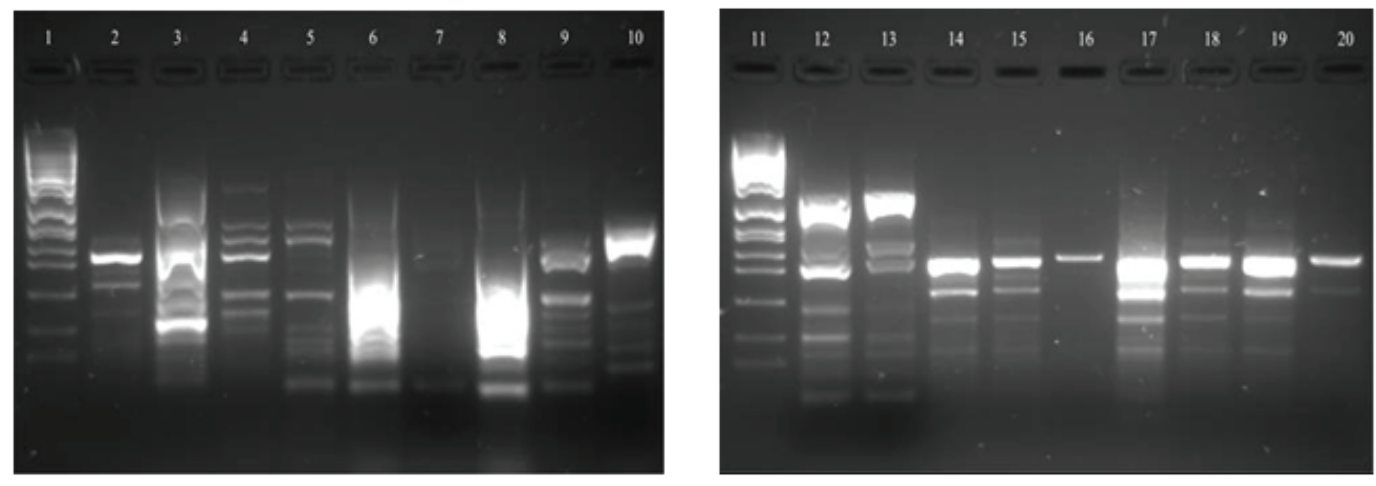

Fig. 6. RAPD-PCR-amplifications of fecal Lactobacillus strains by ACGCGCCCT-primer. Lines 1. and 11.: SPP1 Eco RI molecular weight marker. The bacterial strains used in amplifications on the lines 2.-10. and 12.-20 are the same as in the figure 2 . 


\section{AGRICULTURAL AND FOOD SCIENCE}

M. Tamminen et al. (2012) 21: 182-196

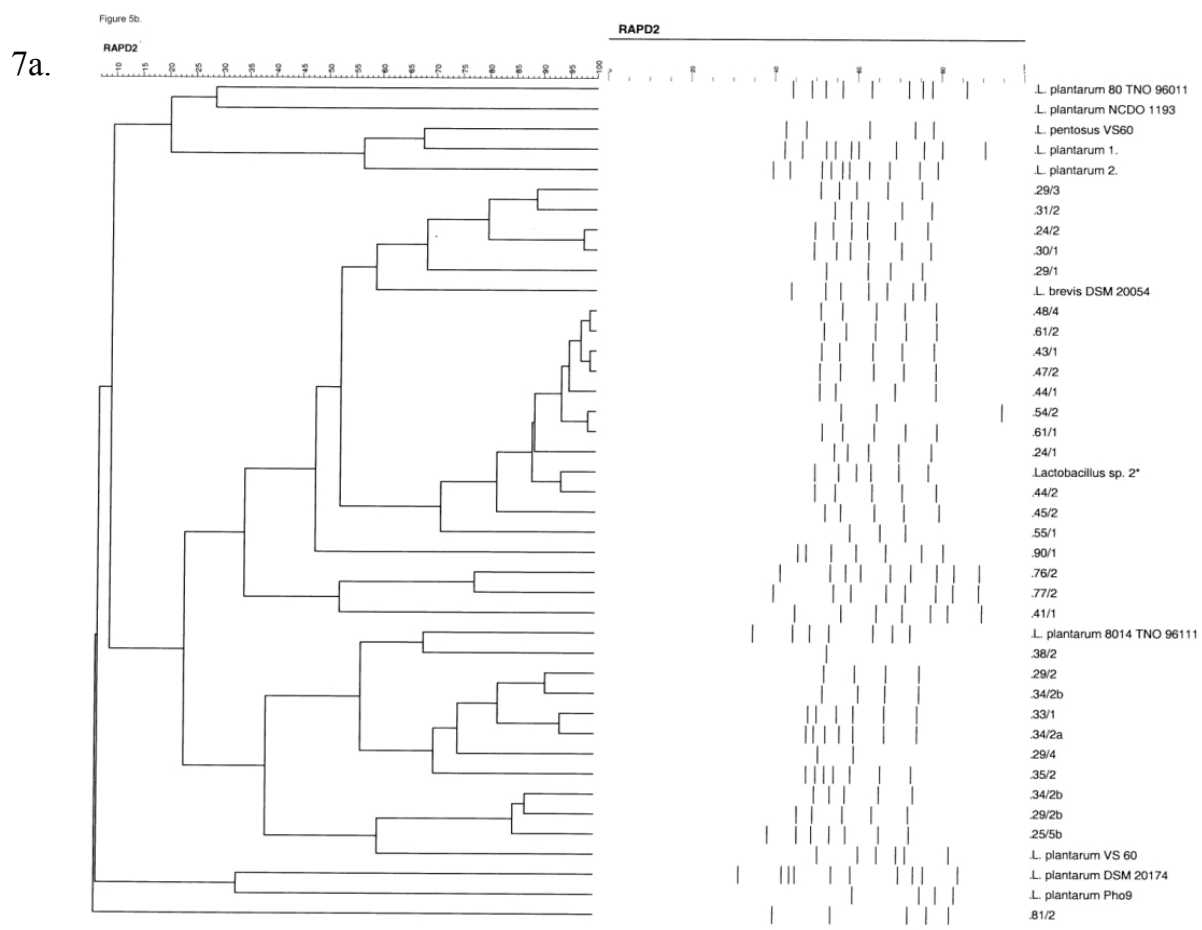

7b. raverse

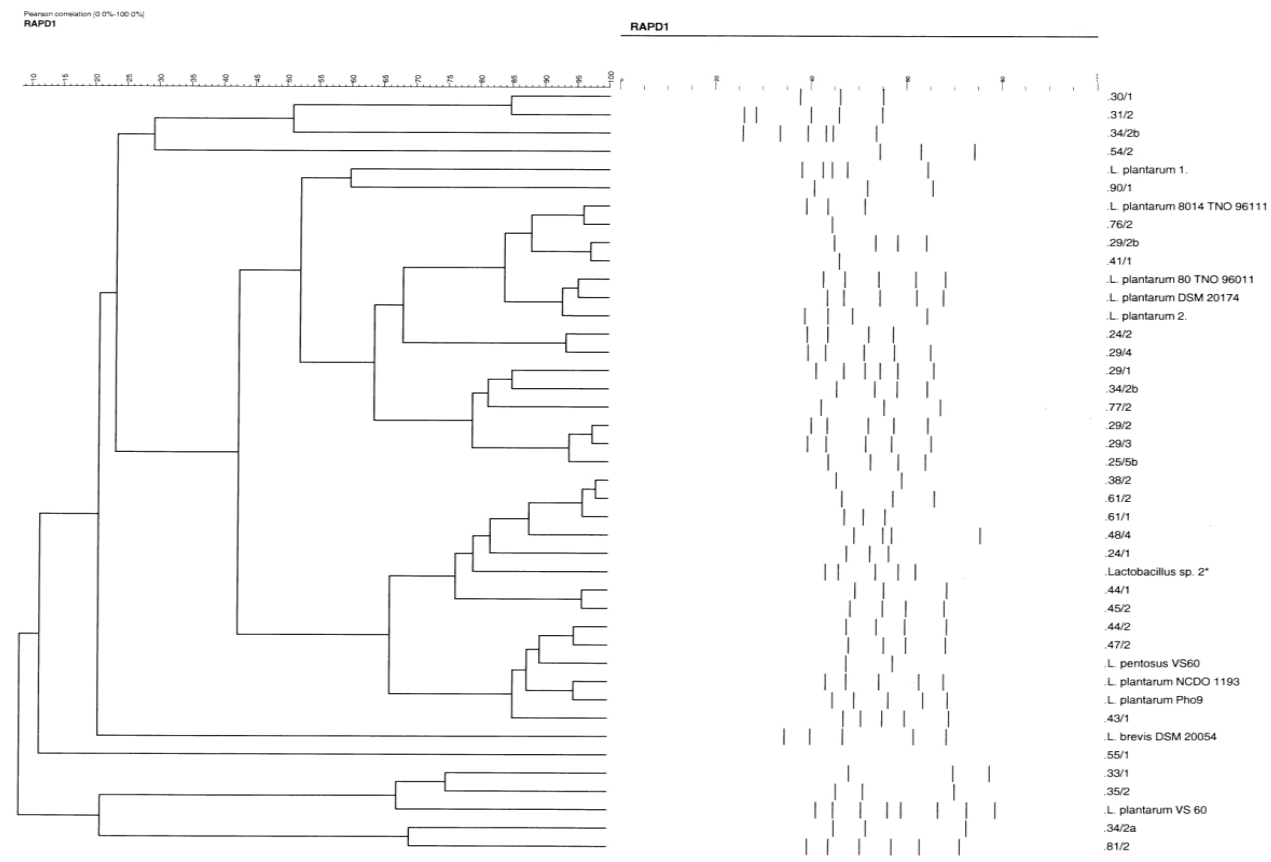

Fig. 7. Cluster analysis of RAPD -PCR with (GTG)5 (7a) and ACGCGCCCT primers (7b). RAPD profiles were analysed by Bionumerics program. 


\section{AGRICULTURAL AND FOOD SCIENCE}

M. Tamminen et al. (2012) 21: 182-196

\section{PFGE -analysis}

The results of PFGE -electrophoresis (Fig. 8) were calculated with UPMGA-system and the position tolerance in analysis was $2 \%$. Twenty seven isolates were analyzed by PFGE-technique and 14 of them had similarity of $100 \%$ with $L$ b. paraplantarum DSM 14485 , seventeen over $99 \%$ similarity and 19 over $95 \%$ similarity. Two isolates of 27 could not be identified. The isolates with $100 \%$ similarity were originated from 13 fecal samples, and five of these isolates were from frozen samples (from five different test subjects). In fecal samples, which were recovered from 10 of the 12 test subjects eating P-diet, several isolates showed over $95 \%$ similarity to $L b$. paraplantarum DSM 14485 (Table 3). All isolates with over 95\% similarity originated from samples of intervention I. Only four isolates had under $95 \%$ similarity with $L b$. paraplantarum DSM 14485 (Fig. 9a and 9b.

Table 3. Number of LAB and $L b$. paraplantarum DSM 14485 in the double blinded cross-over study identified by multiplex-PCR and PFGE calculated as per cent of isolated LAB.

\begin{tabular}{|c|c|c|c|c|c|c|}
\hline \multirow{2}{*}{$\frac{\text { Period }}{\text { Diet }}$} & \multirow[t]{2}{*}{ Basic } & \multicolumn{2}{|c|}{ Intervention I } & \multirow[t]{2}{*}{ Wash-out } & \multicolumn{2}{|c|}{ Intervention II } \\
\hline & & $\mathrm{P}$ & SF & & $\mathrm{P}$ & SF \\
\hline Number of test subjects & 24 & 12 & 10 & 22 & 10 & 12 \\
\hline Number of isolated LAB & 92 & 88 & 80 & 88 & 40 & 44 \\
\hline Strains identified as DSM 14485 & 0 & 19 & 0 & 0 & 0 & 0 \\
\hline $\begin{array}{l}\text { Number of test subject whose fecal samples } \\
\text { contained DSM } 14485\end{array}$ & 0 & 9 & 0 & 0 & 0 & 0 \\
\hline
\end{tabular}

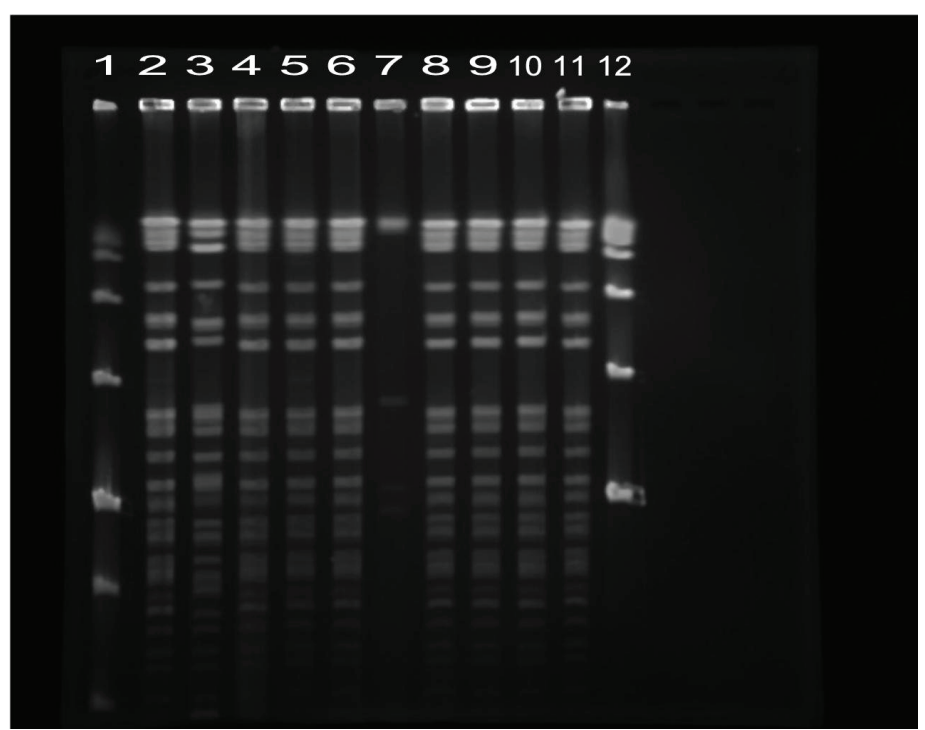

Fig. 8. PFGE -electrophoresis of fecal bacterial strains. Lines 1 and 12: molecular weight markers: line 1 lambda DNA (uncut and Hind III fragments ) and line 12 lambda DNA concatemers. The brightest fragment is $48,5 \mathrm{~kb}$ long. In line 2 is pattern of restricted DNA of $L b$. paraplantarum DSM 14485. Lines 3-11 are restricted DNA patterns of bacterial strains, isolations 29/1, 24/3, 29/3, 30/1, 34/2b, $27 / 2$ b, 29/2b, 4471, 61/1 respectively. 


\section{AGRICULTURAL AND FOOD SCIENCE}

M. Tamminen et al. (2012) 21: 182-196

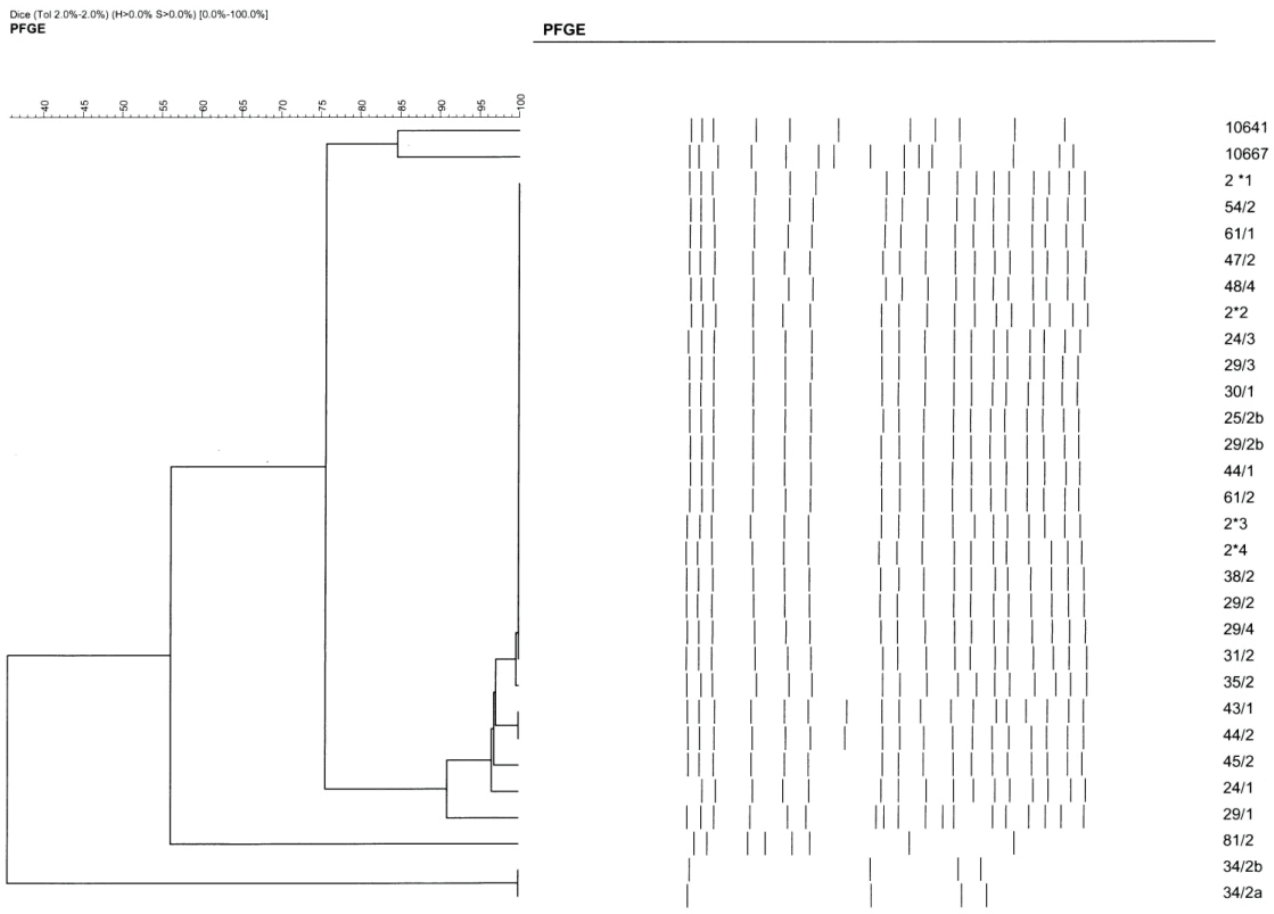

Fig. 9a. Cluster analysis of PFGE -electrophoresis. Samples numbered 10641 and 10667 are Lb. paraplantarum-strains from DSM-collection. $2 * 1,2 * 2,2 * 3$ and $2 * 4$ are $L$ b. paraplantarum DSM 14485 restrictions of separated PFGE -electrophoresis. 81/2 was isolated from a sample of wash out-period of spontaneous fermentation.

$\approx \&$
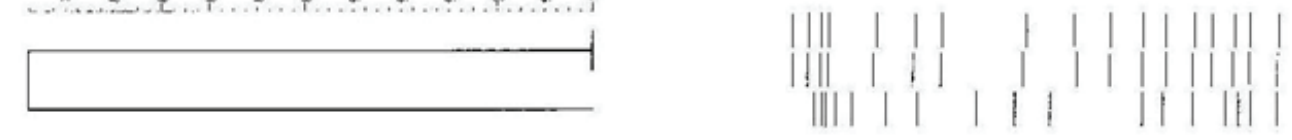

Fig. 9b. Cluster analysis of two isolates $33 / 1$ and 90/1 isolated from a sample of intervention II, starter fermentation. Pattern of $2 * 5$ Lb. paraplantarum DSM 14485 restriction is shown as $2 * 5$. 


\section{AGRICULTURAL AND FOOD SCIENCE}

M. Tamminen et al. (2012) 21: 182-196

\section{Discussion}

PFGE-analysis showed that $L b$. paraplantarum DSM 14485 was able to survive in the human gastrointestinal tract. $L b$. paraplantarum DSM 14485 was found in the feces of the ten persons out of twelve that participated in the intervention studies. PFGE-analysis is a very specific method to identify bacterial strains (Tynkkynen et al. 1999, Simpson et al. 2002). Parameters of electrophoresis which can be changed are potential, pulse time, and running time of electrophoresis. No Lb. paraplantarum DSM 14485 strains were detected in the samples taken before the intervention. All identified Lb. paraplantarum DSM 14485 strains were isolated from intervention I, including frozen fecal samples. Lb. paraplantarum DSM 14485 was not detected in any fecal samples collected from intervention II. Possibly the numbers of active and viable $L A B$ were higher in the Intervention I, since in intervention I products were prepared in two lots except for sauerkraut, which was packed all at once for both interventions, whereas for the intervention II they were prepared in one lot. There is no clear explanation why Lb. paraplantarum 14485 could not be isolated from fecal samples from intervention II. The proportion of isolates identified by PFGE with over $95 \%$ similarity to $L b$.paraplantarum DSM 14485 was approximately $11.0 \%$ of isolates from feces in the end of intervention I, and consequently the frequency of $L b$. paraplantarum was approximately $0.57 \mathrm{lg}$ cfu $\mathrm{g}^{1}$ corresponding $6.6 \%$ of LAB in carrot juice used in interventions I and II.

RAPD-PCR is not a specific method for $L b$. paraplantarum DSM 14485, because this method did not yield $100 \%$ similarity for any isolate in this investigation with both PCR primers. Strains from different species may yield similar profiles and different species may show only few differences e.g. one fragment difference in profiles (Moschetti et al. 2000, Villani et al. 1997). Discrimination power can sometimes be lower than that of API CHL 50 (Johansson et al. 1995b) disagreeing with studies of van Reenen and Dicks (1996), who reported successful differentiations between $L b$. plantarum and $L b$. pentosus strains with RAPD versus carbohydrate fermentations. Rep A-primer (GTG) was also used to distinguish $L b$. plantarum from $L b$. pentosus and $L b$. paraplantarum isolated from fermented vegetable foods from India (Tamang et al. 2005). Despite a limited specificity, RAPD is a useful tool to screen bacterial isolates rapidly. When RAPD-PCR is used as screening method, it is necessary to screen primers for bacterial strains suitable for differentiation. However, RAPD-PCR is fast and economic to screen large numbers of bacteria for further studies so it is useful 1) especially in combination with other techniques for example carbohydrate fermentations or 2) if there is not any optimized method available to identify bacterial strains or 3 ) if carbohydrate fermentations do not differentiate isolates enough to further studies. PCR-ELISA is not as fast as RAPD, but it is a more specific method at family or species level if the probes are well designed. In this case, multiplex-PCR combined with carbohydrate fermentation is enough to identify isolates from same origin and strains which are genetically close to each other. However, species-specific PCR is restricted to specific primers which should be available depending on the bacterial species. Design of primers requires sufficient know how and time. This also applies to PCR-ELISA -method.

\section{Conclusions}

The present study reports the use of a combination of molecular and culture based techniques to successfully determine the survival of a potential probiotic through gastrointestinal transit; a strategy that may be useful also for other strains. In screening of isolates from feces some methods were much more economical and rapid than PFGE: Multiplex-PCR, PCR-ELISA, carbohydrate fermentations and RAPD-PCR. Two latter methods were effective in differentiating isolates without species-specific identification and so they are very useful in screening bacterial strains when species-specific PCR-primers are not available. 


\section{AGRICULTURAL AND FOOD SCIENCE}

M. Tamminen et al. (2012) 21: 182-196

According to PFGE-studies $L b$. paraplantarum DSM 14485 is able to survive in the human intestinal tract. The study suggests that a potential new probiotic strain, suitable for the production of vegetable based probiotic foods has been introduced. This could provide an alternative to the common milk based probiotic foods and extend the range of probiotic products.

\section{References}

Asano, M., Karasawa, E. \& Takayama, T. 1986. Antitumor activity of Lactobacillus casei (LC 9018) against experimental mouse bladder tumor (MBT-2). Journal of Urology 136: 719-21.

Bover-Cid, S. \& Heinrich Holzapfel, W. 1999. Improved screening procedure for biogenic amine production by lactic acid bacteria. International Journal of Food Microbiology 53: 1-80.

Bringel, F., Castioni, A., Olukoya, D.K., Felis, G.E., Torriani, S. \& Dellaglio, F. 2005. Lactobacillus plantarum subsp. argentoratensis subsp. nov., isolated from vegetable matrices, International Journal of Systematic and Evolutionary Microbiology 55: 1629-1634.

Bruce, A.W. \& Reid, G. 1988. Intravaginal instillation of lactobacilli for prevention of recurrent urinary tract infections. Canadian Journal of Microbiology 34: 339-343.

Ehrmann, M., Ludwig, W. \& Schleifer, K.H.1994. Reverse dot blot hybridization: a useful method for direct identification of lactic acid bacteria in fermented food. FEMS Microbiology Letters 117: 143-150.

Gardner, N.J., Savard, T., Obermeier, P., Caldwell, G. \& Champagne, C.P. 2001. Selection and characterization of mixed starter cultures for lactic acid fermentation of carrot, cabbage, beet and onion vegetable mixtures. International Journal of Food Microbiology 64: 261-275.

Gevers, D., Huys, G. \& Swings, J. 2001. Applicability of rep-PRC fingerprinting for identification of Lactobacillus species. FEMS Microbiology Letters 205: 31-36.

Gharaei-Fathabad, E. \& Esmilamifar, M. 2011. Isolation and applications of one strain of Lactobacillus paraplantarum from tea leaves (Camelia sinensis). American Journal of food Technology 6: 429-434.

Hertel, C., Ludwig, W., Obst, M., Vogel, R.F., Hahhes, W.P. \& Schleifer, K.H. 1991. 23S rRNA-targeted oligonucleotide probes for the rapid identification of meat lactobacilli. Systematic and Applied Microbiology 14: 173-177.

Isolauri, E., Joensuu, E., Suomalainen, H., Luomala, M. \&Vesikari, T. 1995. Improved immunogenity of oral DXRRV ressortant rotavirus vaccine by Lactobacillus casei GG. Vaccine 13: 310-312.

Jiang, T. \& Savaiano, D.A. 1997. In vitro lactose fermentation by human colonic bacteria is modified by Lactobacillus acidophilus supplementation. Journal of Nutrition 127:1489-1495.

Johansson, M.-L., Quednau, M., Molin, G. \& Ahrné, S. 1995a. Randomly amplified polymorphic DNA(RAPD) for typing of Lactobacillus plantarum strains. Letters of Applied Microbiology 21:155-159.

Johansson, M.-L., Molin, G., Pettersson, B., Uhlen, M. \& Ahrne, S. 1995b. Characterization and species recognition of Lactobacillus plantarum strains by restriction fragment length polymorphism (RFLP) of the 16S rRNA gene. Journal of Applied Bacteriology 79:536-541.

Joutsjoki, T., Tamminen, M, Mäki, M., Viander, B. \& Ryhänen E.-L. 2003. Starter for fermentation of plant material. WO 03/063612 A1. 31 p.

Jägerstad, M., Jastrebova, J. \& Svensson, U. 2004. Folates in fermented vegetables - a pilot study. LebensmittelWissenschaft und Technologie 37: 603-611.

Kalliomäki, M, \& Isolauri, E. 2002. Pandemic of atopic diseases - a lack of microbial exposure in early infancy? Current Drug Target - Infectious Disorders 2: 193-199.

Kankaanpää, P., Sutas, Y., Salminen, S. \& Isolauri, E. 2003. Homogenates derived from probiotic bacteria provide downregulatory signals for peripheral blood mononuclear cells. Food Chemistry 83: 269-277.

Moschetti, G., Blaiotta, G., Villani, F. \& Coppola, S. 2000. Specific detection of Leuconostoc mesenteroides subsp. mesenteroides with DNA primers identified by randomly amplified polymorphic DNA analysis. Applied and Environmental Microbiology 66: 422-424. 


\section{AGRICULTURAL AND FOOD SCIENCE}

M. Tamminen et al. (2012) 21: 182-196

Mäkimattila, E., Kahala, M. \& Joutsjoki, V. 2011.Charachterization and electrotransformation of Lactobacillus plantarum and Lactobacillus paraplantarum isolated from fermented vegetables. World Journal of Biotechnology 27: $371-379$.

Nissinen, K., El-Nezami, H., Chrevatidis, A., Mykkänen, O., Rauma, A.-L. \& Mykkänen, H. 2003. The health effects of fermented vegetables. Poster presented at New Functional ingredients and Foods (NFIF 2003) 9-11 April 2003, Copenhagen, Denmark.

NMKL 140:1991. Lactic acid bacteria. Determination in meat and meat products.

Parente, E., Ciocia, F., Ricciardi, A., Zotta, T., Felis, G.F. \& Torriani, S. 2010. Diversity of stress tolerance in Lactobacillus plantarum. Lactobacillus pentosus and Lactobacillus paraplantarum: A multivariate screening study. International Journal of Food Microbiology 144: 270-279.

Saxelin, M., Lassig, A., Karjalainen. H., Tynkkynen, S., Surakka, A., Vapaatalo, H., Järvenpää, S., Korpela, R., Mutanen, M. \& Hatakka, K. 2010. Persistence of probiotic strain in gastrointestinal tract when administered as capsules, yoghurt or cheese. International Journal of Food Microbiology 144: 293-300.

Schrezenmeir, J. \& de Verse M. 2001. Probiotics, prebiotics and symbiotics, approaching a definition. American Journal of Clinical Nutrition 73 (Suppl.): S361-S364.

Spicka, J., Kalac, P., Bover-Cid, S. \& Krizek, M. 2002. Application of lactic acid bacteria starter cultures for decreasing the biogenic amine levels in sauerkraut. European Food Research and Technology 215: 509-514.

Simpson, P.J., Stanton, C., Fitzgerald, G.F. \& Ross, R.P. 2002. Genomic diversity within the genus Pediococcus as revealed by randomly amplified polymorphic DNA PCR and pulsed-field gel electrophoresis. Applied and Environmental Microbiology 68: 765-771.

Tamang, J.P., Tamang, B., Schillinger, U., Franz, C. M. A. P., Gores, M. \& Holzapfel, W. H. 2005. Identification of predominant lactic acid bacteria isolated from traditionally fermented vegetable products of the Eastern Himalayas. International Journal of Food Microbiology 105: 347- 356

Tamminen M., Mäki M. and Joutsjoki V. 2003. Differentiation of Lactobacilli related to Lactobacillus plantarum from naturally fermented cucumbers and white cabbage. Applied Biotechnology, Food Science and Policy. 1, 2: 125-128.

Tamminen M, Joutsjoki T, Sjöblom M, Joutsen M, Palva A., Ryhänen E-L and Joutsjoki V. (2004); Screening of lactic acid bacteria from fermented vegetables by carbohydrate profiling and PCR-ELISA, Letters in Applied Microbiology 2004, 39, 439-444.

Temmerman, R., Huys, G. \& Swings, J. 2004. Identification of lactic acid bacteria: culture-dependent and culture independent methods. Trends in Food Science and Technology 15: 348-359.

Tolonen, M., Rajaniemi, S., Pihlava, J.-M., Johansson, T., Saris, P.E.J. \& Ryhänen, E.-L. 2004. Formation of nisin, plantderived biomolecules and antimicrobial activity in starter culture fermentations of sauerkraut. Food microbiology 21: 167-179.

Torriani, S., Clementi, F., Vancanneyt, M., Hoste, B., Dellaglio, F. \& Kersters, K. 2001a. Differentation of Lactobacillus plantarum, L.pentosus, and L.paraplantarum species by RAPD-PCR and AFLP. Systematic and Applied Microbiology 24: 554-560.

Torriani, S., Felis, G. E. \& Dellaglio, F. 2001b. Differentation of Lactobacillus plantarum, L.pentosus, and L.paraplantarum by recA gene sequence analysis and multiplex PCR assay with recA gene-derived primers. Applied and Environmental Microbiology 67: 3450-3454.

Tynkkynen, S., Satokari, R., Saarela, M., Mattila-Sandholm, T. \& Saxelin, M. 1999. Comparison of ribotyping, randomly amplified polymorphic DNA analysis and pulsed-field gel electrophoresis in typing of Lactobacillus rhamnosus and $L$. casei strains. Applied and Environmental Microbiology 65: 3908-3914.

Valerio, F., De Bellis, P., Lonigro, S.L., Morelli, L., Visconti, A. \& Lavermicocca, P. 2006. In vitro and in vivo survival and transit tolerance of potentially probiotic strains carried by artichokes in the gastrointestinal tract. Applied and Environmental Microbiology 72: 3042-3045.

Validov, S. Z., Pankova, N.V., Kozlova, E.V., Kuzmin, N.P., Klimenko, V.V. \& Boronin, A.M. 1998. Rapid identification of Lactobacillus plantarum by RAPD-PCR. Microbiology 67: 317-322.

van Reenen, C.A. \& Dicks L.M.T. 1996. Evalution of numerical analysis of random amplified polymorphic DNA (RAPD) PCR as a method to differentiate Lactobacillus plantarum and Lactobacillus pentosus. Current microbiology 32: $183-187$.

Villani, F., Moschetti, G., Blaiotta G. \& Coppola, S. 1997. Characterization of strains of Leuconostoc mesenteroides by analysis of soluble whole-cell protein pattern, DNA fingerprinting and restriction of ribosomal DNA. Journal of Applied Microbiology 82: 578-588. 


\section{AGRICULTURAL AND FOOD SCIENCE}

M. Tamminen et al. (2012) 21: 182-196

Weymarn, N., Hujanen, M. \& Leisola, M. 2002. Production of D-mannitol by heterofermentative lactic acid bacteria. Process Biochemistry 37: 1207-1213.

Yoon, K.Y., Woodams, E.E. \& Hang, Y.D. 2006. Production of probiotic cabbage juice by lactic acid bacteria. Bioresource Technology 97: 1427-1430. 